\title{
Aprovação de Empréstimos a Governos Subnacionais no Brasil: Há Espaço para Comportamento Político Oportunista?
}

\author{
Paulo Roberto Arvate \\ Ciro Biderman \\ Marcos Mendes
}

\section{INTRODUÇÃO}

$\mathrm{O}$

Brasil é uma Federação composta de 26 estados e um Distrito Federal. A Constituição Federal impõe limites quantitativos e condições qualitativas às quais os governos subnacionais devem atender para serem legalmente autorizados a contratar empréstimos. A Secretaria do Tesouro Nacional - STN e o Senado Federal são as instituições encarregadas de determinar se os governos subnacionais atendem ou não aos padrões fixados na legislação. Neste artigo, testaremos se o tempo necessário para aprovação, no Senado, dos pedidos de autorização para endividamento está correlacionado ou não com variáveis políticas. Se os senadores estivessem simplesmente "seguindo as regras procedimentais", não seria de se esperar a existência de correlação entre o prazo de aprovação e as variáveis políticas.

Há na literatura de economia política uma lista de evidências sobre comportamentos oportunistas em momentos eleitorais. Desde o trabalho de Nordhaus (1975), muitos artigos procuraram investigar se os governos aumentam seus déficits orçamentários antes das eleições para aumentar suas chances eleitorais ${ }^{1}$. A maior parte das evidências das décadas de 1980 e de 1990 respaldava essa possibilidade, demonstrando um comportamento oportunista do Executivo.

DADOS - Revista de Ciências Sociais, Rio de Janeiro, Vol. 51, n-4, 2008, pp. 983 a 1014. 
A literatura empírica referente a países latino-americanos mostra evidências da presença de ciclos eleitorais orçamentários. Ames (1987) documenta um aumento considerável dos gastos no ano que precede a eleição, seguido de uma redução concomitante no ano seguinte. Canitrot (1975), Mejía Acosta e Coppedge (2001), Amorim Neto e Borsani (2004) e Melo (2005) também encontram evidências de ciclos eleitorais orçamentários e de relações causais entre algumas características institucionais dos regimes fiscais dos países e seus gastos públicos e déficits fiscais².

Um importante resultado encontrado na literatura é que a possibilidade de aumentar os gastos e, com eles, o déficit é maior quando o ocupante do cargo tem acesso ilimitado a empréstimos para financiar seus déficits. Como seria de se esperar, a possibilidade de tomar empréstimos ilimitados estimula e amplia os ciclos orçamentários. Para evitar esse problema, muitos países impõem restrições legais ao endividamento público. A questão se agrava em países de regime federativo, em que os governos subnacionais podem assumir empréstimos com garantias federais implícitas ou explícitas ${ }^{3}$. Essas garantias criam uma situação conhecida na literatura como "restrição orçamentária fraca" (soft budget constraint) ${ }^{4}$.

A maior parte da literatura se concentrou na análise da manipulação política e das regras que poderiam tornar o orçamento mais rígido. Que seja de nosso conhecimento, não se dedicou tanta atenção ao estudo de existência ou não de manipulação política das regras de restrição ao endividamento ${ }^{5}$. Pretendemos, com este artigo, preencher parcialmente essa lacuna da literatura.

No Brasil, as regras de controle do endividamento público foram estabelecidas na Constituição Federal de 1988, que conferiu ao Senado Federal a função de impor limites e condições ao endividamento público. No que diz respeito ao controle do endividamento estadual, o Senado conta com o apoio da STN, que atua como órgão assessor. O Senado define os limites (quantitativos e qualitativos). Se um governo subnacional (estadual ou municipal) pretende tomar um empréstimo, deve apresentar a proposta à STN, que, agindo como órgão auxiliar do Senado, analisará a solicitação com base em parâmetros técnicos. Estando a solicitação dentro das conformidades legais, é enviada ao Senado para ratificação. Se rejeitada pela STN, é devolvida ao governo subnacional sem possibilidade de recurso. 
Uma vez que a solicitação chega ao Senado, um senador é destacado como relator pela Comissão de Assuntos Econômicos - CAE. O relatório redigido pelo relator é apresentado no plenário da CAE e, depois, em sessão plenária do Senado para aprovação final. Nosso estudo investiga se há manipulação política interna no Senado a fim de atrasar ou de agilizar processos em função de interesses políticos. $\mathrm{O}$ tempo relevante começa a ser contado a partir do momento em que o pedido chega ao Senado e é considerado como terminado no momento em que é aprovado na plenária do Senado.

Este artigo também está relacionado com o estudo de Spiller e Tommasi (2007) que analisa o equilíbrio político na Argentina ${ }^{6}$. Como esses autores, poderíamos interpretar o sistema de aprovação de endividamento do Senado como um "jogo" entre agentes do Senado e do Executivo. Esse jogo poderia ser dividido em quatro subjogos (sub-games) ou etapas. Na primeira etapa, o presidente da CAE define o relator; na segunda, o relator publica seu relatório; na terceira, o relatório é aprovado ou encaminhado para análise mais aprofundada no plenário da CAE; na última etapa, o relatório é a provado ou devolvido para análise mais aprofundada pelo plenário do Senado. Em cada etapa, há diferentes jogadores que podem ou não estar participando de um jogo cooperativo. Nesse caso, a cooperação significa que o senador segue as regras do processo. A cooperação pode ser atingida em um jogo não-cooperativo se os senadores temerem punição por outros senadores ao deixarem de seguir as regras processuais. Também pode ser atingida se os senadores travarem um jogo cooperativo em que todos elaborem seus relatórios de modo "razoável"7 . Em nosso arcabouço, não é possível inferir se a cooperação (quando observada) resulta de jogo nãocooperativo, com punição, ou de jogo cooperativo.

Como todas as solicitações encaminhadas ao Senado passam antes pelo crivo da STN, em uma análise (supostamente) técnica das regras, resta pouco espaço para o veto sumário às solicitações. Entretanto, observamos em nossa amostra uma dispersão considerável do prazo de ratificação, o que levanta a hipótese de que a manipulação política pode estar sendo feita mediante aceleração (ou postergação) da aprovação dos pedidos com maior (ou menor) suporte político.

É claro que a diferença de prazos de aprovação pode estar ligada a muitos fatores "não-políticos". Se assim fosse, poderíamos não identificar correlação entre o prazo de ratificação e as variáveis políticas. Assim, 
testar a correlação entre prazo de aprovação e variáveis políticas é um meio de testar o comportamento oportunista ou não dos senadores nessas comissões, ou, em jargão de teoria dos jogos, testar se o jogo é ou não cooperativo ${ }^{8}$.

A principal conclusão deste artigo é que alguns fatores políticos se encontram correlacionados com o prazo de aprovação no Senado. Diversas variáveis mostraram coeficientes não-significativos. As variáveis consistentemente correlacionadas com o prazo de aprovação são a ligação política entre o governador do Estado solicitante e o relator; e o acúmulo excessivo de solicitações nos seis meses anteriores a um novo pedido. Quando o governador e o relator pertencem à mesma coalizão, o processo se acelera. Se o relator pertencer à mesma coalizão que o governador, mas ocorrer uma mudança que encerre essa ligação (por exemplo, uma mudança de relator, sendo o novo relator não-pertencente à coalizão do governador), o processo passa a tramitar mais devagar. Interpretamos esse resultado como evidência de comportamento oportunista por parte de alguns senadores ou, em jargão de teoria dos jogos, como evidência de ausência de cooperação entre governadores e relatores que não pertençam à mesma coalizão política.

Apesar de cada pedido de autorização de endividamento pelos Estados ser analisado individualmente, os senadores podem estar menos inclinados a aprovar solicitações de Estados que as apresentem em número excessivo ou que tenham aprovado recentemente um grande número de empréstimos. No jogo político, atos que favoreçam excessivamente um Estado ou governador podem perturbar o equilíbrio de forças políticas existente na Federação. De fato, constatamos que Estados que enviam muitas solicitações em um curto espaço de tempo precisam, em média, esperar mais tempo pela aprovação de suas demandas.

No que diz respeito às variáveis que não apresentaram coeficientes significativos, é possível que não tenhamos conseguido defini-las de forma a espelhar, satisfatoriamente, o comportamento estratégico dos senadores. Outra explicação possível para a escassez de evidências de influência política é que o aperfeiçoamento das regras de controle ao longo dos anos (descrito adiante) pode ter limitado o espaço para manipulação política (as reformas do processo de controle teriam sido bem-sucedidas na preservação dos critérios técnicos, reduzindo a possibilidade de influência política). 
Outra possibilidade é que o poder da STN tenha aumentado com as novas regras; com isso, a barganha política, em vez de ser feita no Senado, talvez se tenha deslocado para dentro da STN. Essa é uma questão a ser explorada em outro estudo. No momento, não há dados disponíveis para testar tal hipótese.

Este artigo está dividido em cinco seções, sendo a primeira delas esta introdução. A segunda seção trata do processo de aprovação de empréstimos adotado pelo Senado e fornece um panorama da evolução institucional das regras de endividamento subnacional que puseram fim à falta de controle federal sobre as dívidas subnacionais. A seção seguinte descreve o jogo que ocorre no Senado e que pode influenciar no prazo de aprovação de solicitações de empréstimos pelos Estados. Também trata da fonte da influência política que poderia afetar o processo de autorização e define as variáveis explicativas. O principal conceito é o "elo político" definido pela coincidência de coalizão entre jogadores. A quarta apresenta os resultados empíricos e discute brevemente as limitações da análise. A análise econométrica sugere haver apenas um equilíbrio não-cooperativo em todo o processo senatorial. A última seção enfatiza esse resultado e fornece alguns argumentos possíveis para compreender o quebra-cabeça que essa interpretação implica. Também afirma haver outras interpretações possíveis para o resultado obtido e conclui com a proposição de uma agenda de pesquisa sobre a relação entre o federalismo fiscal brasileiro, as regras internas do Senado, políticas partidárias e de coalizões.

\section{FEDERALISMO FISCAL BRASILEIRO E APROVAÇÃO DE EMPRÉSTIMOS SUBNACIONAIS}

A Constituição Federal de 1988 estabelece limites máximos e condições de endividamento público dos governos estaduais ${ }^{9}$. A Constituição atribui ao Senado a função de controlar o endividamento estadual, uma vez que a principal função do Senado é cuidar do equilíbrio entre unidades da Federação ${ }^{10}$. Composto de três representantes de cada um dos Estados e do Distrito Federal, a missão do Senado é restabelecer o equilíbrio de forças na Federação, dado que o número de assentos na Câmara dos Deputados é mais proporcional à população de cada Estado. Assim, o Senado é, por natureza, o foro para discussão e eventual solução de conflitos federativos. Conseqüentemente, é o Senado que controla o endividamento dos Estados, assegurando que alguns pou- 
cos não imponham ao restante do país o ônus de um endividamento excessivo.

Desde meados da década de 1980 o Brasil evoluiu de uma situação de elevado desequilíbrio fiscal nos governos municipais, estaduais e federal para um estado de equilíbrio sólido. Foram estabelecidas diversas instituições que favoreceram a responsabilidade fiscal e reduziram os incentivos ao endividamento (irresponsável) do setor público. As regras de controle do endividamento por parte do Senado evoluíram no mesmo sentido, passando de meras declarações de intenção para um controle relativamente eficaz.

Até o começo da década de 1990, a política fiscal havia sido marcada por uma sucessão de resgates financeiros proporcionados pelo governo federal a Estados e municípios. Os Estados eram proprietários de bancos freqüentemente usados para fins políticos e sem a devida atenção a normas básicas de solvência ${ }^{11}$. O resultado freqüente era a falência dessas instituições que, no entanto, se mantinham solventes graças a aportes significativos dos tesouros estaduais ou, mais usualmente, do tesouro federal.

Com o Plano Real, implementado em 1994, encerrou-se o regime de inflação elevada e a taxa de juros real explodiu, dificultando o financiamento dos déficits dos governos estaduais. Com isso, o governo federal implementou um plano de resgate para refinanciar letras e outras dívidas dos Estados, atrelando o refinanciamento a um rigoroso programa de ajuste fiscal e à amortização da dívida junto ao Tesouro Nacional ao longo de um período de trinta anos. As condições desse empréstimo estabeleciam sanções muito severas para os que deixassem de atender a suas obrigações. Governos estaduais que deixassem de pagar uma única parcela da dívida poderiam ter suas contas bancárias bloqueadas, de modo que o Tesouro pudesse retirar delas o que lhe era devido.

Esses contratos, firmados ${ }^{12}$ em torno de 1997, anunciaram o começo de uma nova era de controle do endividamento público. Do ponto de vista do Senado, a janela de oportunidade para aumentar a eficácia do controle sobre o endividamento dos Estados se abriu em 1996. Uma Comissão Parlamentar de Inquérito - CPI descobriu uma série de fraudes na emissão e na negociação de títulos públicos estaduais. Naquele momento, dado o número excessivo de títulos estaduais no mercado, o Senado somente aprovava a emissão de novos títulos para financiar o pa- 
gamento de precatórios dos Estados ${ }^{13}$. Por isso, alguns Estados criaram fraudulentamente condenações inexistentes para obter autorização para emitir letras. Além disso, descobriu-se que essas emissões fraudulentas estavam associadas a esquemas de negociação no mercado secundário que eram igualmente fraudulentos e geravam perda de recursos públicos e lucros para alguns bancos e corretoras.

A exposição ao público das fraudes nas sessões da CPI criada para investigá-las permitiu aprovar diversas melhorias da legislação de controle do endividamento pelo Senado. Em 1998, foi aprovada a Resolução 78, que introduziu as seguintes mudanças:

a) O relator da solicitação de endividamento não poderia ser do Estado solicitante. O principal motivo para isso se baseava no temor de que um governador do mesmo Estado e da mesma coalizão tendesse a aprovar solicitações que não cumprissem as regras de endividamento ou, em caso de rivalidade política, que a decisão fosse adiada.

b) A obrigação de que o órgão de assessoria (Banco Central até 2000 e a STN de 2000 em diante) declarasse claramente a conformidade ou não da solicitação com as normas. Antes de 1998, o órgão de assessoria do Senado freqüentemente emitia relatórios com conclusões ambíguas, abrindo a possibilidade de negociação política pela aprovação no Senado.

c) Solicitações que não atendessem aos requisitos legais seriam devolvidas ao Estado solicitante e consideradas rejeitadas. Anteriormente, tais casos seriam remetidos ao Senado e possivelmente autorizados mediante negociação política.

d) Proibição de diversos tipos de operação que, de maneira camuflada, permitiam que Estados e municípios aumentassem seus níveis de endividamento. Um exemplo típico era a contratação de obras públicas sem recursos fiscais correspondentes. O governo firmava com a empreiteira um termo de compromisso de pagamento futuro ${ }^{14}$. Outro exemplo era a emissão de debêntures de empresas estatais estaduais, seguida de uso dos recursos para pagamento adiantado de impostos ao Estado controlador da estatal.

e) A partir de 1999, operações que envolvessem a antecipação de recursos orçamentários - créditos bancários de curto prazo - passariam a ser obrigatoriamente realizadas por leilão eletrônico centralizado no Banco Central. Essas regras se justificavam porque essas operações eram uma fonte de endividamento excessivo e de cor- 
rupção. Um pequeno grupo de bancos dominava o mercado, oferecendo recursos a custo elevado a governos de pequenas cidades que não tinham capacidade técnica para tomar dinheiro por conta própria ou avaliar as propostas que firmavam.

f) Proibição de tomada de empréstimos nos seis últimos meses de mandato do governador ou do prefeito.

g) Proibição de emissão de novos títulos públicos até 2010.

h) Obrigação de Estados e municípios com mais de 50 mil habitantes a fornecer periodicamente informações financeiras à STN. Esta, por sua vez, ficou obrigada a divulgar essas informações pela internet.

i) Proibição do regime de urgência para avaliação de pedidos de autorização de endividamento. O regime de urgência, que acelerava o processo no âmbito do Senado, reduzia o tempo disponível para análise técnica da solicitação de empréstimo, facilitando a aprovação de solicitações em desacordo com as exigências legais.

Posteriormente, a Lei de Responsabilidade Fiscal ${ }^{15}$, cujo objetivo era estabelecer padrões de gestão pública voltados para a estabilidade fiscal, levou à substituição do Banco Central pela STN na função de órgão de assessoria do Senado. Essa substituição foi importante porque o Banco Central, ao ser incluído entre os órgãos públicos responsáveis pelo controle da dívida dos Estados, era muitas vezes chamado a emitir títulos ou moeda para realizar operações de resgate. A escolha do Tesouro Nacional também foi estratégica, já que o órgão também era responsável pela administração dos contratos de refinanciamento da dívida dos Estados. Concentrar em uma só instituição todas as informações relevantes acerca das finanças dos Estados e dar a ela autoridade legal para impor restrições ao endividamento estadual aumentou a eficácia do órgão de assessoria.

A partir de 2001, quando foram consolidadas todas essas novas re gras $^{16}$, passaram a ser submetidos ao Senado apenas os seguintes tipos de operação de crédito: empréstimos externos; emissão e rolagem de títulos de dívida pública; emissão de bônus por empresas públicas que não gozassem de autonomia financeira; contratos de empréstimo para compra de bens e serviços do exterior. Todos os demais tipos de operação de crédito passam a ser analisados e aprovados (ou rejeitados) exclusivamente pela STN. Pode-se dizer que, ao restringir a análise a esses tipos de empréstimo, os senadores passaram a estudar mais detalhadamente as operações com maior potencial de geração de riscos 
para a Federação. O histórico brasileiro de crises de câmbio implica a necessidade de mais cautela ao analisar a dívida externa. Um endividamento excessivo em letras, por outro lado, pode gerar uma crise no mercado financeiro, algo que já ocorreu em meados da década de 1980. Finalmente, a emissão de debêntures, hoje rara, foi caracterizada no passado por corrupção ou pela superação dos limites de endividamento, justificando sua inclusão entre as operações que exigem análise por parte do Senado.

Atualmente, o procedimento para autorização de operações de crédito começa com o envio da solicitação à STN, que avalia se o pleito atende às restrições de endividamento. Satisfeitas essas condições, a STN encaminha a solicitação ao Senado. O presidente da CAE distribui a solicitação a um senador que será o relator do pedido. O relatório é então analisado e votado pelo plenário da CAE e, finalmente, em sessão plenária do Senado.

\section{0 "JOGO" POLÍTICO NO SENADO}

Todas as solicitações enviadas ao Senado no período analisado foram aprovadas. Mesmo na década de 1980, quando o Senado analisava quase qualquer tipo de operação de crédito e o órgão de assessoria (o Banco Central na época) não gozava de autonomia para rejeitar solicitações (mesmo as que estivessem em desacordo com os limites eram enviadas ao Senado), muito poucas solicitações foram rejeitadas. O motivo para isso era possivelmente político. Os senadores provavelmente praticavam uma política de reciprocidade segundo a qual um senador não votaria contra empréstimos ao Estado de outro para que o representante desse Estado não votasse, no futuro, contra o Estado do primeiro ${ }^{17}$. As reformas descritas anteriormente tiveram como principal objetivo diminuir as chances de aprovação de solicitações fiscalmente irresponsáveis. Tendo em vista a atual situação fiscal, aparentemente as reformas foram bastante bem-sucedidas ${ }^{18}$.

Assim, a variância da aprovação de solicitações enviadas ao Senado é bastante baixa (quase todas as solicitações são aprovadas). No entanto, a variância do prazo de aprovação após o encaminhamento ao Senado é bem elevada. Uma solicitação pode ser aprovada em apenas um dia ou demorar até 636 dias. Trata-se, claro, de casos extremos e a maioria das solicitações é aprovada em menos de 200 dias: apenas 24 de 530 pedidos levaram mais de 200 dias para serem aprovados. Mesmo descon- 
siderados os 24 valores extremos, o desvio padrão do número de dias necessários para aprovação no Senado ainda permanece em torno de 80 dias, revelando uma ampla variância. A diferença no prazo de aprovação pode estar ligada a eventos aleatórios ou a interesses políticos.

Se o prazo de aprovação de uma solicitação estiver correlacionado com determinados fatores políticos que caracterizam cada solicitação (como a coincidência na coalizão ou no partido entre o Estado do governador solicitante e o relator; ter ou não ter ligações políticas com o presidente; entre outros), isso pode ser evidência de que o mecanismo de controle de dívidas não é neutro. Ou, em outras palavras, que pode ser influenciado por fatores políticos.

Entendemos por "fatores políticos" aqueles que levam a negociações não associadas com o objetivo principal do mecanismo de controle sobre endividamento (preservar a liquidez e a solvência das contas públicas), em que a prerrogativa senatorial de "criar dificuldades" para aprovação de uma solicitação é usada por senadores para "vender facilidades". Não falamos aqui de corrupção, mas do uso do mecanismo de controle de dívidas para obter ganhos políticos, como uma manipulação oportunista à luz do ciclo eleitoral, conforme mostra a literatura. Por exemplo, um aumento dos recursos para seu próprio Estado ou uma posição vantajosa em disputas eleitorais vindouras.

É importante observar que o procedimento de aprovação discutido anteriormente, após a apresentação da solicitação ao Senado, envolve quatro etapas: 1) o presidente da CAE nomeia um relator; 2) o relator apresenta um relatório; 3) a solicitação é votada na CAE; 4) a solicitação é votada no plenário do Senado. Nas duas primeiras etapas, um só senador tem poder sobre o prazo de aprovação; primeiro o presidente da CAE e, depois, o relator. Nas etapas 3 e 4, muitos senadores têm influência sobre o prazo de aprovação. Em jargão da teoria dos jogos, dizemos que o "jogo" inclui quatro "subjogos". Em cada subjogo (etapa), o governador do Estado solicitante terá de jogar com um ou mais senadores. A cada etapa pode haver um "equilíbrio político cooperativo" em que os senadores seguem os procedimentos de praxe por medo de que futuras solicitações de sua própria coalizão (ou de seu próprio Estado) não sigam pelos caminhos normais (semelhante ao equilíbrio de logrolling da aprovação anteriormente discutido ${ }^{19}$ ). No entanto, há um "equilíbrio político não-cooperativo" em que os senadores atrasam ou aceleram estrategicamente solicitações, dependendo de suas 
preferências políticas. Se o equilíbrio for cooperativo, não veremos correlação entre o prazo de aprovação e fatores políticos.

Um fator político que pode influenciar na duração de um processo no contexto dos procedimentos normais é uma disputa entre regiões ${ }^{20}$. Há grande desigualdade social e econômica entre os Estados e as regiões do Brasil. Os Estados de menor renda têm maioria no Senado (os Estados do Norte e do Nordeste têm a menor renda per capita e, juntos, 59\% dos assentos no Senado). Pode haver um jogo político em andamento nesse ponto, em que os Estados mais pobres usam sua maioria política para obter vantagens econômicas dos Estados mais ricos. Assim, senadores dos Estados mais pobres podem criar dificuldades quando se trata de aprovar solicitações dos Estados mais ricos. A Tabela 1 a seguir mostra a desigualdade de renda entre as regiões do Brasil:

Tabela 1

Renda Média per capita (1989-2001) das Diferentes Regiões do Brasil

\begin{tabular}{l|c}
\hline Regiões & Renda Média per capita \\
\hline Centro-Oeste & 5,61757 \\
Norte & 3,984658 \\
Nordeste & 2,793445 \\
Sul & 7,392105 \\
Sudeste & 8,375497 \\
São Paulo (Sudeste) & 9,835952 \\
\hline
\end{tabular}

Fonte: Instituto de Pesquisa Econômica Aplicada - Ipea.

Nota: Valores em milhares de reais e deflacionados pelo deflator implícito no Produto Interno Bruto - PIB (base $=2000)$.

Os Estados da região Sudeste apresentam a mais elevada renda per capita do Brasil. O Estado de São Paulo, por exemplo, que pertence a essa região, é o mais rico do país e tem renda per capita superior à média da região. Dada essa situação, os senadores podem não ver com bons olhos a autorização de dívida para uma região mais rica (Sudeste) ou para o Estado mais rico (São Paulo), seja porque tais operações financiariam uma maior expansão da economia da região ou do Estado, seja porque os representantes de outros Estados podem agir em bloco contra solicitações da região mais rica como meio de negociar vantagens fiscais para seus próprios Estados ${ }^{21}$. Por isso, testamos se solicitações 
do Nordeste, do Centro-Oeste e do Norte foram aprovadas mais rapidamente do que outras.

A existência de influência política também pode ser vista no número de solicitações feitas por Estado. Apesar de cada processo ser analisado individualmente, os senadores teriam menor tendência a aprovar solicitações de Estados que as apresentem em número excessivo ou que tenham tido um grande número de empréstimos aprovado recentemente. No jogo político, atos que favoreçam excessivamente um Estado ou governador em particular poderiam alterar o equilíbrio de forças políticas presente na Federação. A autorização de empréstimo para um governo estadual representa uma extensão de sua restrição orçamentária e um acúmulo de capital político que pode ser usado nas eleições.

Embora o prazo de aprovação seja definido pelo Legislativo, o presidente da República costuma ter influência sobre o Congresso. Assim, uma solicitação apresentada por um governador aliado do presidente, por exemplo, poderia adquirir peso político e ser aprovada mais rapidamente desde que o presidente contasse com maioria sólida e fiel no Senado. Entretanto, se o presidente não contar com tal maioria no plenário ou na $\mathrm{CAE}$, seus aliados podem se deparar com prazos de aprovação mais longos. O senador usaria esse poder (temporário) para obter outros benefícios, como financiamento federal para projetos de interesse de sua própria base eleitoral ${ }^{22}$. Nesse caso, o resultado seria um maior atraso da análise de solicitações de governadores ligados ao presidente. Quase metade das solicitações apresentadas ao Senado (47\%) apresenta alguma ligação entre o governador e o presidente.

Neste artigo, definimos um "elo político" entre dois políticos quando ambos concorreram nas eleições anteriores como membros de uma só coalizão partidária. Com essa definição, podemos passar a estabelecer relacionamentos capazes de afetar o processo decisório do Senado, admitindo que haja influência política sobre o prazo de aprovação. Além da ligação entre o governador do Estado solicitante e o presidente, também consideramos o elo político entre o governador solicitante e o presidente da CAE e o senador nomeado relator do processo.

O elo político entre o governador solicitante e o presidente da CAE poderia afetar o prazo de aprovação, dado que é o presidente da CAE quem define o relator, como visto anteriormente. Se o presidente da CAE pretender dificultar a aprovação, pode escolher como relator um senador que compartilhe da mesma intenção (ou seja, adiar ao máximo 
a aprovação). O presidente da CAE também tem o poder de adiar ou acelerar a própria definição do relator, por meio da concessão de prazos regimentais para análise ("pedidos de vistas"). Pode ainda conceder ao relator uma prorrogação de prazo para que avalie mais detidamente o processo. Cerca de $40 \%$ das solicitações apresentadas ao Senado trazem algum elo entre o governador solicitante e o presidente da CAE.

O elo político entre o governador solicitante e o relator também pode influenciar no prazo de aprovação. O relator é sempre um membro da CAE e deve apresentar um relatório indicando à comissão se recomenda ou não a aprovação do empréstimo a um Estado específico. O relator é o senador que analisa detalhadamente a solicitação. Muito embora a STN já tenha dado seu parecer de conformidade da solicitação com a legislação, um relator que deseje criar problemas pode divergir do parecer do Tesouro e sugerir que a análise do órgão tenha sido descuidada. O relator também pode divergir e produzir argumentos contra o investimento que seria financiado com o empréstimo em tela. Por outro lado, um relator aliado ao governador interessado no empréstimo poderia acelerar o processo e apresentar um relatório não muito detalhado em um prazo mínimo. Dos 530 processos submetidos à apreciação do Senado, $43 \%$ apresentavam elo político entre o governador solicitante e o relator.

Tendo em mente que a disputa eleitoral pelo Senado se dá no âmbito de cada Estado (o distrito eleitoral, segundo as normas brasileiras) e que o (atual) senador pode concorrer futuramente ao cargo de governador, não só os elos partidários mas também o "elo estadual", definido para abranger os casos em que os dois políticos pertençam ao mesmo Estado, podem afetar a análise das solicitações de endividamento. De maneira mais fraca, o "elo regional", que se define por dois políticos pertencentes à mesma região, pode influenciar no prazo de aprovação. Embora mais fraco, usamos o elo regional em vez do estadual porque desde 1998 não se permite que o relator seja do Estado solicitante e desejamos manter a consistência no uso da variável ao longo do tempo. Assim, controlamos para o elo regional entre o presidente da CAE e o governador do Estado solicitante e para o elo regional entre o relator e o governador, interagindo cada "elo regional" com o "elo político". É de se esperar que um senador pertencente à mesma coalizão eleitoral e à mesma região do governador solicitante esteja mais interessado em 
minimizar a duração do prazo de aprovação do que um senador que apenas pertença à mesma coalizão.

\section{ANÁLISE EMPÍRICA}

Neste artigo, usamos um método dedicado à análise do prazo decorrido, chamado de duration (duração), até que se dê um dado evento. Esse método foi originalmente desenvolvido a partir do que se chama survival analysis (análise de sobrevivência), inicialmente aplicada na área médica em estudos de sobrevida de pacientes submetidos a determinado tratamento ou acometidos por determinada doença. Na análise de sobrevivência, estamos interessados em como diversos tratamentos ou características demográficas afetam o tempo de sobrevivência. Os artigos seminais no campo são os de Cox e Oakes (1984), Kalbfleisch e Prentice (1980) e Lancaster (1990) ${ }^{23}$. Em nossa análise, estamos interessados em entender como variáveis políticas estão ligadas à "sobrevivência" da solicitação no Senado. Ou seja, em todos os modelos usados, a probabilidade de que o Senado atrase a aprovação em $t$ dias pode ser entendida como função sobrevivente da solicitação: uma solicitação com maior prazo de sobrevivência é aquela que leva mais tempo para ser aprovada. Estamos interessados sobretudo em testar a presença de correlação entre sobrevivência e variáveis políticas.

Outro conceito fundamental é a função risco. Essa função mede a razão entre a probabilidade de uma determinada solicitação em particular ser aprovada e a função de sobrevivência (não-aprovação de uma solicitação) em um dado intervalo de tempo. A análise empírica a seguir considera todas as solicitações apresentadas ao Senado entre 1989 e 2001.

Começamos a análise pela apresentação dos resultados de um teste não-paramétrico da amostra que emprega o método Kaplan-Meier. Vamos partir da função risco de toda a amostra. Essa função, extraída dos dados referentes a solicitações de empréstimos aprovadas pelo Senado Federal, consta do Gráfico 1 a seguir.

O eixo vertical representa o risco/tempo; o horizontal, o tempo. Como esperado, a probabilidade de aprovação aumenta com a duração da estada no Senado. Empregando o método de Kaplan-Meier, a função de sobrevivência pode ser vista no Gráfico 2. 
Aprovação de Empréstimos a Governos Subnacionais no Brasil...

\section{Gráfico 1}

Função Risco da Sobrevivência de uma Solicitação de Autorização de Empréstimo no Senado Dado o Tempo de Análise (dias)

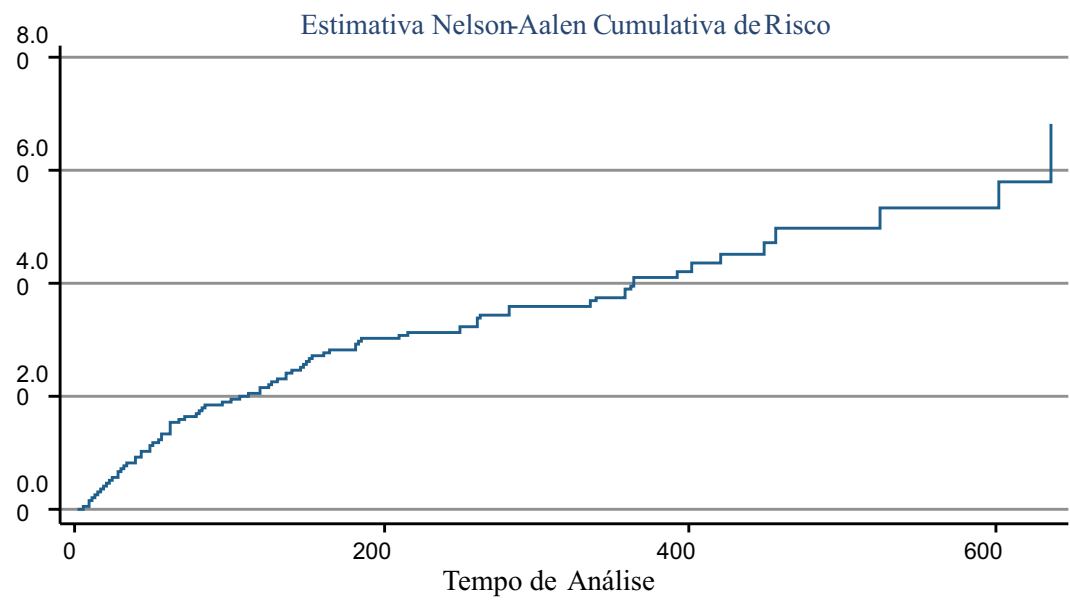

Elaboração dos autores.

\section{Gráfico 2}

Função Sobrevivência de uma Solicitação de Autorização de Empréstimo no Senado Dado o Tempo de Análise (dias)

Método Kaplan-Meier

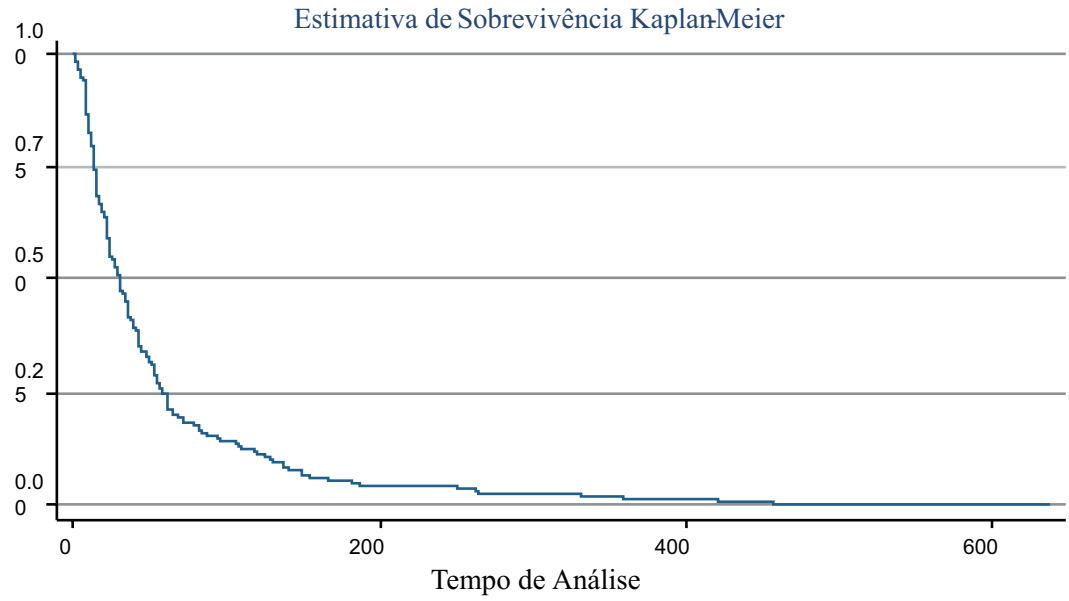

Elaboração dos autores.

A curva da função sobrevivência é suave e próxima da origem. Quatrocentos dias após a apresentação ao Senado, a chance de uma solicitação ainda não ter sido aprovada é quase zero. A maioria das solicitações 
apresentadas ao Senado foi aprovada em menos de 200 dias. Embora a análise não-paramétrica (non-parametric) descreva as características do processo de aprovação em geral, estamos mais interessados em entender se há fatores políticos (tais como definidos na seção anterior) que afetam a sobrevivência da solicitação no Senado.

Nosso principal objetivo é verificar se há influência política sobre o prazo necessário para aprovação de um empréstimo no Senado. Para testar essa correlação, precisamos adotar modelos paramétricos e semiparamétricos que nos permitam acrescentar co-variantes aos testes. Em suma, como visto anteriormente, a hipótese nula é de que não há qualquer relação entre prazo de aprovação e variáveis políticas. Se houver um equilíbrio logrolling do prazo de aprovação ou cooperação no âmbito do Senado, este seria o resultado esperado de fato. Cabe lembrar que, neste artigo, afirmamos haver diversos subjogos durante o processo de aprovação, cada um com diferentes jogadores. Como não observamos cada um dos subjogos, mas apenas o momento de apresentação da solicitação ao Senado e o momento de sua aprovação, nossas variáveis políticas buscam captar o impacto dos diferentes jogadores. O sinal e a significância das co-variantes podem sugerir o equilíbrio nos diferentes subjogos.

Como descrito anteriormente, na primeira etapa, o presidente da CAE nomeia o relator. Para captar o elo político entre o governador do Estado solicitante e o presidente da CAE, usamos uma dummy que assume valor 1 se o senador presidente da CAE pertencer à mesma coalizão que elegeu o governador e valor 0 caso contrário. Chamamos a essa variável GovPresCAE. Se esperamos que o elo possa reduzir o prazo de aprovação, a quebra do elo poderia ter o efeito contrário. O elo pode ser rompido por motivos eleitorais. Entre 1989 e 2001 houve três eleições para os cargos de governador e senador (1990, 1994 e 1998) e três para o de presidente $\left(1989,1994\right.$ e 1998) ${ }^{24}$. Ademais, a presidência da CAE se alterna entre os senadores, e o presidente da comissão pode ser derrotado por outros motivos durante seu mandato. A quebra do elo é representada por outra dummy (GovPresCAEChange), que assume valor 1 apenas se o elo original for positivo (GovPresCAE $=1)$, mas se tenha quebrado durante a aprovação, seja por uma mudança da presidência da CAE, do governador ou de ambas. O elo político entre o governador do Estado solicitante e o relator é captado por duas dummies semelhantes, uma para o começo do processo (GovSen) e outra para captar os efeitos de uma alteração do elo (GovSenChange). Mais uma vez GovSen 
assume valor 1 se o relator no princípio do processo for da mesma coalizão que elegeu o governador e 0 caso contrário. GovSenChange segue o mesmo critério, isto é, assume valor 1 apenas se GovSen for 1 e o elo político tiver sido rompido antes da aprovação. O elo entre o relator e o governador pode mudar por motivos eleitorais, mas também pode se alterar durante o processo por meio de solicitação do presidente da CAE, por solicitação do relator (que desiste de relatar a matéria) ou por mudança na composição da CAE (o relator deixa de ser membro da comissão).

Além dos jogos travados no Senado, acreditamos que o Executivo federal também participe do jogo por meio da influência exercida sobre a Câmara Alta. Como foge ao escopo deste artigo analisar o caminho do presidente (da República) até o Senado e dali para o governador, procuramos captar o elo direto entre o governador solicitante e o presidente da República. Para tanto, agimos exatamente da mesma maneira que na análise anterior e usamos duas dummies, GovPres e GovPresChange. É preciso ter em mente, contudo, que usar o mesmo conjunto de variáveis para analisar a influência política do presidente sobre a aprovação pode ser simplista. Por exemplo, se o presidente for fraco no âmbito da $\mathrm{CAE}$, pertencer à coalizão do presidente pode até aumentar o prazo de aprovação. Voltaremos a essa questão mais adiante.

Na última etapa, a solicitação é submetida ao plenário da CAE e, finalmente, ao Senado em sessão plenária. Em outras palavras, nessa fase, qualquer senador pode aumentar o prazo de aprovação. Como a composição política da CAE poderia refletir a do Senado, acreditamos que esses dois jogadores "compostos" sejam semelhantes. Usamos duas variáveis que procuram revelar as preferências do Senado. Com a variável GDPpercapita, procuramos captar, por meio da renda per capita estadual (base $=2000$ ), um possível viés político contra os Estados de maior renda. Como já foi dito, pode haver uma tendência dos Estados de regiões mais pobres para operar politicamente contra solicitações de empréstimos de regiões mais ricas. Também procuramos usar as variáveis regionais diretamente; porém, obtivemos resultados contraditórios que não são apresentados neste artigo $^{25}$.

A variável Nnumber procura captar se os senadores atrasariam processos em curso normal se observassem um número excessivo de solicitações do mesmo Estado. Como vimos, atos que favorecem um Estado ou governador em particular podem alterar o equilíbrio político da Fede- 
ração. Autorizar um empréstimo a um governo estadual significa flexibilizar sua restrição orçamentária imediatamente após a aprovação e representa um acúmulo de capital político que pode ser usado no momento das eleições. Como os senadores podem estar voltados para o curto prazo, essa variável mede o número de solicitações apresentadas por Estado nos seis meses anteriores. Embora essa variável possa refletir preferências gerais, também revela a posição do relator e pode até ser razoável do ponto de vista técnico. Um relator que se depare com uma solicitação que conte com outras simultâneas ou que tenham saído recentemente do Senado pode desejar analisar os relatórios anteriores, o que pode complicar o processo.

Além das variáveis políticas e econômicas, também usamos uma variável de controle (Res78) que assume o valor 1 após a implementação da Resolução 78. Como descrito anteriormente, houve uma queda significativa do número de solicitações apresentadas ao Senado após a aprovação dessa legislação. Como a Resolução representa uma alteração profunda do procedimento, podendo distorcer nossa análise, controlamos para essa mudança institucional.

Partimos de um modelo semiparamétrico (semi-parametric). A principal vantagem desse tipo de modelo está em não assumir uma distribuição a priori dos resíduos. Também testaremos quatro distribuições alternativas dos resíduos em uma estimação paramétrica (parametric) discutida mais adiante. A principal preocupação no que tange à abordagem paramétrica é que a distribuição (assumida) pode estar incorreta. Nesse caso, os coeficientes ficariam viesados. Por outro lado, se a distribuição estiver correta, os coeficientes seriam estimados com maior precisão. As estatísticas básicas de todas as variáveis usadas constam do Apêndice A (Tabela A.1). A Tabela 2 a seguir mostra os resultados semiparamétricos.

A razão de risco associada às co-variantes na abordagem semiparamétrica apresenta a direção esperada. É importante observar que valores superiores a 1 movem a função de risco básica para cima, implicando uma probabilidade reduzida de que a solicitação permaneça no Senado (expectativa de aprovação mais rápida). Valores inferiores a 1 movem a função risco básica para baixo, implicando maior probabilidade de que a solicitação permaneça no Senado (expectativa de aprovação tardia). Assim, vemos que, quando o presidente da CAE e o governador pertencem à mesma coalizão (GovPresC $A E$ ), a aprovação é mais rá- 
Aprovação de Empréstimos a Governos Subnacionais no Brasil...

Tabela 2

Resultados do Modelo de Risco Proporcional Semiparamétrico do Prazo de Aprovação de uma Solicitação de Empréstimo

(1989-2001)

\begin{tabular}{l|c|c|c|c}
\hline Variável & Razão de Risco & Erro Padrão & Teste-Z & Valor-P \\
\hline GovPresCAE & 1,1172 & 0,1126 & 1,10 & 0,271 \\
GovPresCAEChange & 0,8642 & 0,1684 & $-0,75$ & 0,454 \\
GovSen & 1,4500 & 0,1457 & 3,70 & 0,000 \\
GovSenChange & 0,1827 & 0,0369 & $-8,41$ & 0,000 \\
GovPres & 0,9968 & 0,0997 & $-0,03$ & 0,974 \\
GovPresChange & 0,8222 & 0,1274 & $-1,26$ & 0,206 \\
GDPpercapita & 0,9906 & 0,0178 & $-0,53$ & 0,598 \\
Nnumber & 0,9377 & 0,0292 & $-2,07$ & 0,039 \\
Res78 & 1,0085 & 0,1158 & 0,07 & 0,941 \\
\hline
\end{tabular}

Notas: Modelo Cox de risco proporcional estimado pela probabilidade máxima. Valores superiores a 1 movem a função de risco básica para cima, implicando menor probabilidade de permanência da solicitação no Senado. Valores inferiores a 1 movem a função básica de risco para baixo, implicando maior probabilidade de permanência da solicitação no Senado. Número de observações: 530; razão probabilística: $\chi^{2}(9)=106,58 ; \log$ probabilístico $=-2664,4342$.

pida; quando rompido esse elo, a velocidade da aprovação se reduz. $\mathrm{O}$ mesmo comportamento pode ser observado em relação ao elo entre o governador e o relator (GovSen). Assim, a direção observada em cada etapa do processo é consistente com a idéia de que tanto o presidente da CAE quanto o relator beneficiariam seus parceiros e de que um rompimento do elo geraria uma punição.

Como estamos trabalhando com estimação de máxima verossimilhança, podemos interpretar as estatísticas de teste- $Z$ como testes de significância dos parâmetros. Tomando o parâmetro-Z, da Tabela 2, e o valor-P correspondente, vemos que o elo entre o relator e o governador (ou o rompimento desse elo) é significante a 1\%, enquanto o elo entre o governador e o presidente da CAE (ou seu rompimento), embora apresente a direção esperada, não é significante nem sequer a 10\%. Esses resultados sugerem que pode haver um equilíbrio cooperativo, por meio de cooperação "pura" ou logrolling, nas etapas em que o presidente da CAE é um dos principais jogadores (juntamente com o governador) e algum tipo de não-cooperação entre um governador e um relator que não sejam aliados políticos. No entanto, a não-significância do elo (ou sua ausência) entre o presidente da CAE e o governador pode ser atribuída à impossibilidade de estimação precisa em uma estrutura semiparamétrica fundada em distribuições assintóticas. 
O elo político entre o presidente da República e o governador, bem como sua quebra, não é significante a 10\%. Como a influência do presidente sobre o prazo de aprovação é indireta, os resultados podem apenas revelar que a relação entre o presidente e a comissão pode mudar durante o período (em momentos de presidente da República com grande base no Senado, o apoio do presidente aceleraria o processo e vice-versa).

A variável que procura captar o impacto da composição da CAE e do Senado sobre o prazo de aprovação (GDPpercapita) também apresenta a direção esperada. Os prazos de aprovação são mais longos para os Estados mais ricos do que para os mais pobres; porém, a estimação da razão é imprecisa. Em outras palavras, essa variável sugere que a composição do Senado (que se presume semelhante à da CAE) não afeta o prazo de aprovação. Também testamos o impacto da composição usando regiões geográficas e os resultados foram contraditórios (regiões sobre-representadas apresentam prazos de aprovação mais longos), mas de estimação imprecisa.

Por outro lado, Estados com maior número de solicitações nos seis meses anteriores seriam punidos com maiores prazos de aprovação. Esse resultado pode sugerir que o Senado pune Estados que procuram ampliar "muito rapidamente" suas bases de investimento. Essa variável não está diretamente ligada à composição do Senado, mas indiretamente. A maioria dos senadores, mesmo que pertença à mesma coalizão, não estaria disposta a aumentar "excessivamente" a base de investimento de um Estado qualquer. Infelizmente, como vimos, o acúmulo de solicitações em processo de aprovação pode atrasar a aprovação, uma vez que os relatores e até mesmo a própria CAE podem desejar coordenar as aprovações, já que elas podem exercer um impacto (endógeno) umas sobre as outras. Dado que o prazo médio de aprovação é de três meses, as solicitações acumuladas nos seis meses anteriores tendem a se sobrepor. Esse segundo argumento é mais técnico do que político.

Assim, a direção das variáveis políticas é normalmente a esperada, mas a maioria das estimações é imprecisa, exceto no caso do elo político entre o governador e o relator e pelo acúmulo de solicitações. Vale a pena testar a consistência da regressão reproduzindo o equivalente de um teste-F no contexto de OLS. Para assumir que o modelo semiparamétrico com risco proporcional (e suas co-variantes) represente o que 
efetivamente ocorre com as solicitações de autorização apresentadas ao Senado, precisamos checar se a adoção da hipótese de proporcionalidade do risco (uma hipótese fundamental para o modelo semiparamétrico aqui adotado) é viável. A Tabela A.2 do Apêndice A mostra o teste Schoenfeld dos resíduos.

O teste $\chi^{2}$ indica que precisamos rejeitar a hipótese de risco proporcional das co-variantes. Investigamos mais a fundo para verificar quais co-variantes nos impediam de adotar a hipótese. Os resultados constam da Tabela A.3. São duas as co-variantes que impedem a adoção da hipótese do risco proporcional: GovPresChange e GovSenChange. As demais covariantes permitiriam o risco proporcional.

Há, portanto, duas preocupações ligadas à abordagem semiparamétrica. Primeiro, alguns dos coeficientes não são estimados com precisão. Segundo, a hipótese do risco proporcional não é totalmente sustentada pelos dados. Uma abordagem paramétrica poderia adotar outra hipótese quanto à função risco, como uma forma logarítmica do risco relativo. A estimação também pode ser mais eficiente. Assim, estimamos a mesma especificação adotando uma abordagem paramétrica que usa quatro distribuições diferentes para os resíduos: exponencial, Weibull, log-normal e log-logística. Os resultados são apresentados na Tabela 3 a seguir.

Os resultados das funções exponencial e Weibull foram estimados com a forma logarítmica do risco relativo, enquanto os das funções log-normal e log-logística o foram com uma forma de tempo de fracasso acelerado $^{26}$. É importante notar que os resultados das duas primeiras distribuições (exponencial e Weibull) são apresentados em termos da razão de risco, enquanto os das duas outras (log-normal e log-logística) o são em termos dos coeficientes. A interpretação das razões de risco é a mesma dada às razões na abordagem semiparamétrica. Os coeficientes apresentados para as outras duas distribuições nas duas últimas colunas, por outro lado, devem ser interpretados da forma usual, ou seja, um sinal negativo implicaria redução do prazo de aprovação. Em outras palavras, os coeficientes estimados referem-se ao efeito marginal das co-variantes sobre a duração esperada do processo no âmbito do Senado. Coeficientes negativos indicam que a variável explicativa reduz a duração, enquanto os positivos prolongam a duração esperada.

Infelizmente os resultados paramétricos não forneceram estimativas suficientemente precisas para alterar as conclusões anteriores. As va- 
Tabela 3

Resultados Paramétricos com Diferentes Funções

\begin{tabular}{|c|c|c|c|c|}
\hline \multirow[t]{2}{*}{ Variável } & \multicolumn{4}{|c|}{ Distribuição } \\
\hline & Exponencial & Weibull & Log-normal & Log-logística \\
\hline \multirow[t]{2}{*}{ GovPres CAE } & 1,1643 & 1,1664 & $-0,0878$ & $-0,0320$ \\
\hline & $(0,1170)$ & $(0,1177)$ & $(0,1059)$ & $(0,1007)$ \\
\hline \multirow[t]{2}{*}{ GovPresCAEChange } & 0,8100 & 0,8073 & 0,0264 & $-0,0022$ \\
\hline & $(0,1547)$ & $(0,1549)$ & $(0,2009)$ & $(0,1924)$ \\
\hline \multirow[t]{2}{*}{ GovSen } & $1,5080^{*}$ & $1,5131^{*}$ & $-0,2826^{*}$ & $-0,2983^{*}$ \\
\hline & $(0,1508)$ & $(0,1535)$ & $(0,1044)$ & $(0,0998)$ \\
\hline \multirow[t]{2}{*}{ GovSenChange } & $0,1560^{*}$ & $0,1544^{*}$ & $2,1097^{*}$ & $2,0607^{*}$ \\
\hline & $(0,0293)$ & $(0,0301)$ & $(0,2009)$ & $(0,1804)$ \\
\hline \multirow[t]{2}{*}{ GovPres } & 1,0399 & 1,0409 & 0,0591 & 0,0937 \\
\hline & $(0,1039)$ & $(0,1041)$ & $(0,1057)$ & $(0,1023)$ \\
\hline \multirow[t]{2}{*}{ GovPresChange } & 0,8566 & 0,8560 & 0,1857 & 0,1931 \\
\hline & $(0,1325)$ & $(0,1325)$ & $(0,1612)$ & $(0,1554)$ \\
\hline \multirow[t]{2}{*}{ GDPpercapita } & 0,9963 & 0,9965 & 0,0180 & 0,0240 \\
\hline & $(0,0178)$ & $(0,0178)$ & $(0,0200)$ & $(0,0194)$ \\
\hline \multirow[t]{2}{*}{ Nnumber } & $0,9230^{*}$ & $0,9224^{*}$ & $0,0645^{* * *}$ & $0,0633^{* * *}$ \\
\hline & $(0,0285)$ & $(0,0287)$ & $(0,0341)$ & $(0,0340)$ \\
\hline \multirow{2}{*}{$\operatorname{Res} 78$} & 0,9808 & 0,9808 & 0,0251 & $-0,0034$ \\
\hline & $(0,1124)$ & $(0,1125)$ & $(0,1232)$ & $(0,1203)$ \\
\hline \multirow[t]{2}{*}{ Constant } & - & - & $3,0016^{*}$ & $2,9858^{*}$ \\
\hline & - & - & $(0,1541)$ & $(0,1499)$ \\
\hline Observações & 530 & 530 & 530 & 530 \\
\hline$\chi^{2}(9)$ & 163,73 & 141,93 & 115,03 & 124,38 \\
\hline \multirow[t]{3}{*}{ Log-probabilidade } & $-781,068$ & $-781,048$ & $-764,186$ & $-759,477$ \\
\hline & & $\mathrm{P}=1,0064$ & $/$ ln_sig. $=-0,5271$ & $/$ ln_sig. $=-0,5271$ \\
\hline & & $1 / \mathrm{P}=0,9936$ & Sigma $=0,5903$ & Sigma $=0,5903$ \\
\hline
\end{tabular}

Notas: As razões de risco das distribuições exponencial e Weibull, isto é, valores superiores a 1, movem a função básica de risco para cima, implicando probabilidade reduzida de permanência da solicitação no Senado. Coeficientes das distribuições log-normal e log-logística, isto é, valores negativos, movem a função básica de risco para cima, implicando probabilidade reduzida de permanência da solicitação no Senado. Desvio padrão entre parênteses. ${ }^{*},{ }^{* *} \mathrm{e}^{* * *}$ correspondem aos níveis de significância de $1 \%, 5 \%$ e $10 \%$, respectivamente, usando testes-Z.

riáveis significativas permanecem sendo ou a existência ou a ausência de elo político entre o relator e o governador (GovSen, GovSenChange) e o acúmulo de solicitações (Nnumber).

A direção dos impactos do elo político entre o presidente da CAE e o governador (GovPresCAE, GovPresCAEChange) permanece consistente, exceto no caso das distribuições log-normal e log-logística, em que a mudança desse elo diminui o prazo de aprovação. No entanto, esse re- 
sultado contraditório não é significativo nem sequer a $10 \%$. Os resultados quanto ao elo com o presidente da República (GovPres, GovPresChange) continuam contraditórios e não são estimados com precisão em qualquer uma das distribuições.

O elo político entre o relator e o governador é maior do que 1 nas distribuições exponencial e Weibull; negativo para log-normal e log-logística; e estimado com precisão a 1\%. O resultado inverso é encontrado quando a relação muda (GovSenChange). Os resultados revelam que o processo não segue seu curso normal, considerando que o elo político entre o relator e o governador aumenta o prazo de aprovação e o fim desse elo diminui o prazo de aprovação.

Os resultados para os coeficientes de solicitações acumuladas são menores do que 1 (distribuições exponencial e Weibull - a 1\%) e positivos (distribuições log-normal e log-logística - a 10\%). Os resultados também revelam um desvio em relação aos procedimentos normais, considerando que, quanto maior o número de solicitações nos seis meses antecedentes, maior a "duração" até a aprovação. Ou seja, os senadores (de modo geral) também podem estar travando um jogo não-cooperativo. Contudo, precisamos considerar que o motivo do atraso para Estados com muitas solicitações de empréstimo também pode ter bases técnicas.

Podemos selecionar o melhor modelo entre as distribuições (escolhidas arbitrariamente) como aquele que apresenta o maior logaritmo da máxima verossimilhança (melhor modelo preditivo) ou usando o critério do mínimo de informação de Akaike e os resíduos Cox-Snell. Os resultados dos critérios de máxima verossimilhança e Akaike (últimas duas linhas da Tabela 3) indicam que poderíamos escolher o modelo log-normal ou o log-logístico. Os resíduos sugerem que o modelo $\log$-logístico resultaria em melhor encaixe do que o log-norma $1^{27}$. No entanto, a escolha da distribuição dos resíduos não é relevante, nesse caso, porque os resultados são robustos em face de mudanças da forma funcional e apontam para a mesma direção que as estimativas do modelo semiparamétrico de risco proporcional.

\section{CONCLUSÃO E CAMINHOS FUTUROS DE PESQUISA}

Neste artigo, foi investigado o equilíbrio político nas diversas etapas do processo de autorização do endividamento estadual pelo Senado Federal. Após aprovação pelo órgão de assessoria (STN, atualmente), alguns empréstimos aos Estados precisam passar por diversas etapas 
no Senado, começando pela CAE e encerrando em sessão plenária do Senado. Durante esse processo, diferentes jogadores têm o poder em potencial de aumentar ou diminuir o prazo de aprovação. Usamos, neste estudo, modelos econométricos de duração no tempo para testar se determinadas variáveis políticas estão correlacionadas com o prazo de aprovação de uma solicitação de endividamento estadual ao Senado. Procurando testar o impacto dos diferentes jogadores que representam papéis significativos nas diversas etapas do processo, definimos os elos políticos relacionados ao presidente da CAE, ao relator do processo e ao Senado.

O elo político (pertencer à mesma aliança política que ajudou a eleger o governador) entre o governador (solicitante do empréstimo) e o relator reduz o tempo de permanência da solicitação no Senado. Um "relator amigável" poderia apresentar "rapidamente" um relatório favorável, incentivando a aprovação acelerada da solicitação. Essa conclusão seria consistente com a explicação anterior se o rompimento do elo prolongasse o prazo de aprovação. Foi exatamente isso o observado. Uma mudança desse elo está associada a um maior atraso da aprovação. Tal resultado é obtido tanto em uma estimação semiparamétrica quanto em estimações paramétricas usando quatro distribuições diferentes dos resíduos. Também se mostrou robusto em face de mudanças da especificação $0^{28}$.

O acúmulo de solicitações também reflete um viés político do prazo de aprovação, considerando que, quanto maior o número de solicitações nos seis meses anteriores à solicitação em tela, maior o prazo até sua aprovação. Em outras palavras, os senadores podem estar travando aí um jogo não-cooperativo, e o resultado se confirma com quatro distribuições diferentes dos resíduos.

O elo político entre o governador solicitante e o presidente da CAE se apresentou sempre na direção correta, mas nunca com significância a 10\%. O mesmo resultado foi observado em relação ao PIB per capita. Acreditamos que a falta de precisão provavelmente não está ligada ao método de estimação, mas não podemos ter certeza de que está ou não ligada ao tamanho da amostra. Admitindo que não se trata de um problema de amostragem, a falta de precisão poderia significar que os elos políticos com o presidente da CAE e a composição do Senado não afetam o prazo de aprovação de uma solicitação. Nesse caso, podemos lançar a hipótese de que haja um equilíbrio (político) cooperativo nas 
etapas em que o presidente da CAE, o plenário da comissão ou o plenário do Senado jogam com o governador dos Estados solicitantes; e que haja um equilíbrio (político) não-cooperativo entre o relator e o governador.

Não está claro por que haveria um equilíbrio não-cooperativo entre o relator e o governador, e essa possível conclusão deve ser investigada quanto à sua robustez. Neste artigo, é sugerido que esse equilíbrio não-cooperativo ocorra apenas em uma das etapas do processo. Entender a razão da não-cooperação nessa etapa é uma tarefa de considerável importância para a compreensão do federalismo fiscal brasileiro e de sua interação com o Legislativo e o Executivo federais, assim como do funcionamento de uma das principais comissões senatoriais. Pesquisas futuras devem procurar aumentar a robustez dos resultados, mas também especificar melhor o processo. Por exemplo, a definição dada à coalizão é crucial para a definição dos elos políticos aqui referidos, mas os elos políticos apresentam outras categorias além de coalizão eleitoral e podem mudar com o tempo. Refinar a variável coalizão por meio do acréscimo de dinâmica, ou mesmo de sua divisão em categorias (coalizão eleitoral, coalizão de governo etc.), poderia aprofundar nosso entendimento do processo e a robustez dos resultados.

Mesmo admitindo um equilíbrio político não-cooperativo entre o relator e o governador, estamos muito longe da identificação das causas desse equilíbrio. Poderíamos nos beneficiar de estudos de caso com alguns processos de aprovação. Por exemplo, pode ser que seja mais fácil para o relator do que para qualquer outro agente do jogo reclamar para si o crédito por uma rápida aprovação. De fato, os senadores, com exceção do relator, não gozam de muitos meios para acelerar o processo. A maior parte de seu poder estaria ligada ao postergamento da aprovação.

Por outro lado, é possível argumentar que o jogo entre relator e governador se dá apenas entre dois jogadores, enquanto os demais subjogos ocorrem entre diversos jogadores (incluindo o relator) ao mesmo tempo. Costuma ser mais fácil obter cooperação quando há poucos jogadores, mas esse resultado "teórico" admite ser mais fácil observar as ações com menos jogadores. Um senador que não seja relator pode atrasar uma aprovação por meio do expediente de pedido de vistas do processo. Com isso, um ato praticado por um senador não-relator para adiar uma aprovação é sempre observado, e provavelmente é mais fácil atrasar a apresentação de um relatório do que pedir vistas. Em ou- 
tras palavras, embora haja menos jogadores no subjogo entre relator e governador, pode ser mais difícil observar atos não-cooperativos de um relator do que de um membro da CAE ou de qualquer senador, dados os atuais procedimentos.

É mais complicado entender a insignificância do elo político entre o governador e o presidente da CAE. Podemos lançar a hipótese de que o presidente da CAE não esteja disposto a se envolver em tais negociações, concentrando-se em transações mais relevantes. Há também a possibilidade de que o relator tenha mais poder do que o presidente da CAE para atrasar ou adiantar a aprovação. Assim, ainda que o presidente da CAE esteja procurando atrasar (ou acelerar) aprovações, o resultado não é significativo em face do impacto causado pelo relator por causa da diferença de poder entre os dois para esse determinado fim.

Além disso, pode ser que a melhoria anteriormente descrita das regras de controle tenha limitado o espaço disponível para manipulação política (as reformas foram bem-sucedidas na preservação dos aspectos técnicos do processo, reduzindo a possibilidade de influência política), a não ser para o relator ${ }^{29}$. A outra possibilidade é que, dado o aumento do poder da STN para aprovar ou rejeitar solicitações, a barganha política se tenha deslocado do Senado para o Tesouro. Esse é um ponto a ser investigado em outro estudo. Não há, no momento, dados disponíveis para testar essa hipótese.

Os resultados observados quanto ao elo político entre o governador e o presidente da República não podem ser interpretados da mesma maneira que os resultados para o Senado ou para o presidente da CAE. Como visto, o presidente não exerce influência direta sobre o prazo de aprovação. Seu poder depende da influência que tenha sobre o Senado e sobre a CAE especificamente. Assim, um desdobramento importante dessa pesquisa seria entender a relação entre o presidente da República e a comissão. Por exemplo, construir uma variável que informe se o presidente é fraco ou não no ambiente da CAE e interagir essa variável com o elo político com o governador poderiam revelar o papel que o presidente representa no processo.

De maneira geral, acreditamos que este artigo inaugure uma agenda de pesquisa que procura entender o federalismo fiscal brasileiro e sua relação com o equilíbrio político entre o Senado e o Executivo federal. Interpretamos nossos resultados como preliminares. Ainda há avanços importantes a serem feitos quanto a definição das variáveis e a mo- 
delagem. A natureza dinâmica do processo foi indiretamente captada pelo número de solicitações acumuladas por Estado. O resultado sugere que haja alguma correlação no tempo, mas nosso modelo não permite aprofundar tal aspecto. Os diversos elos foram modelados uniformemente, mas as relações nem sempre são uniformes. Mesmo que nossos resultados preliminares fossem aceitos, ainda haveria um longo caminho a trilhar para entender o porquê da ausência de cooperação entre relator e governador. Considerando que o equilíbrio normal no Senado é do tipo logrolling, permanece um enigma a ausência de logrolling nessa relação em particular.

(Recebido para publicação em outubro de 2007)

(Versão definitiva em outubro de 2008)

\section{NOTAS}

1. No modelo de Rogoff (1990), esse tipo de comportamento é compatível com as expectativas racionais. Ver também Lächler (1984).

2. Esses artigos também investigam como as variáveis fiscais são afetadas por características políticas institucionais, como: preferências ideológicas do presidente e seu partido; presença de uma coalizão majoritária no Congresso; e a divisão de poder entre o Executivo e o Legislativo em questões fiscais. Embora os artigos apresentem alguns resultados contraditórios, o ciclo político fica confirmado.

3. Ter-Minassian (1997) mostra como diferentes federações lidam com esse problema.

4. Ver Kornai (1986).

5. Na década de 1990, havia grande interesse na análise da eficácia das restrições ao endividamento quanto aos déficits fiscais. Ver, por exemplo, Poterba (1996) e Von Hagen (1991). Ainda assim, esses artigos não estudaram a manipulação política das regras.

6. Gostaríamos de agradecer a um avaliador anônimo por nos chamar a atenção para essa literatura.

7. Esse ponto foi levantado por um avaliador anônimo, embora com diferente jargão. O argumento do avaliador era o de que os políticos não tomam decisões com base apenas em seus próprios interesses, o que, nesse contexto, interpretamos como significando que os senadores poderiam travar um jogo cooperativo.

8. Existe uma tradição de trabalhos sobre a alocação de recursos públicos pelo Congresso. Ver Ames (1995), Samuels (1998), Bezerra (1999), Pereira e Rennó (2001), Figueiredo e Limongi (1999) e Souza (2003).

9. Mais precisamente, os limites se aplicam não apenas aos Estados, mas também ao governo federal e aos municípios (art. 52, incisos V a IX). Este artigo se dedica ao controle da dívida dos Estados. 
10. Ver Neiva (2006) a respeito dos poderes das Câmaras Altas.

11. Para o caso brasileiro, ver Bevilaqua (2002); para um histórico da América Latina, ver Stein (1999).

12. Ver Kugelmas, Sallum Jr. e Graeff (1989).

13. A dívida decorrente, por exemplo, da expropriação de terras para a construção de obras públicas ou o passivo trabalhista dos Estados. Essas dívidas eram de grande monta e não havia como honrá-las a não ser com recursos da receita corrente, sendo essa a razão para a autorização excepcional de novos títulos.

14. Empréstimos desse tipo são conhecidos como "precatórios"; representavam uma das práticas mais comuns de aumento do endividamento à margem do sistema financeiro.

15. Lei Complementar, $\mathrm{n}$ - 101, de 2000.

16. A regulamentação consolidada se encontra nas Resoluções 40 e 43, ambas de 2001 .

17. Esse tipo de equilíbrio é chamado de logrolling. Mendes (1999) analisa o fenômeno detalhadamente.

18. Pode ser que a decisão política de aprovação se tenha simplesmente deslocado para a STN. Neste artigo, não analisamos a primeira etapa do processo de aprovação.

19. Os senadores também podem estar travando um "jogo cooperativo" em que nenhum deles aceleraria ou postergaria estrategicamente qualquer solicitação por causa, por exemplo, de considerações éticas.

20. Ver Souza (2003).

21. Um exemplo dessa situação se deu em 1994, quando o Estado de São Paulo conseguiu convencer o governo federal a criar um plano de resgate para o Banco do Estado de São Paulo - Banespa, que estava virtualmente falido. Representantes dos demais Estados vetaram a aprovação do empréstimo federal ao Estado de São Paulo para salvar o banco e, com isso, conseguiram, em 1997, forçar o governo federal a lançar um plano de resgate para todos os bancos estaduais.

22. Ver Pereira e Mueller (2002) a respeito das relações entre Executivo e Legislativo, demonstrando que, no Brasil, o presidente da República recompensa os legisladores que mais votam de acordo com seus interesses.

23. Wooldridge (2001) é um bom ponto de partida para os tratamentos mais avançados mencionados anteriormente.

24. Como Fernando Collor de Mello sofreu impeachment, houve na verdade quatro presidentes no período.

25. Resultados disponibilizados mediante solicitação.

26. Trata-se de uma transformação das medidas que não causa diferença de interpretação em termos dos riscos proporcionais. Ver Kiefer (1988).

27. Os resíduos de cada função podem ser disponibilizados mediante solicitação aos autores.

28. Resultados disponibilizados mediante solicitação aos autores.

29. Essa hipótese, no entanto, perde força na medida em que nossa amostra se concentra em um período anterior à Resolução 78 . 


\section{REFERÊNCIAS BIBLIOGRÁFICAS}

AMES, Barry. (1987), Political Survival. Berkeley, CA, University of California Press. . (1995), "Electoral Strategy under Open-List Proportional Representation". American Journal of Political Science, vol. 39, no 2, pp. 406-433.

AMORIM NETO, Octavio e BORSANI, Hugo. (2004), "Presidents and Cabinets: The Political Determinants of Fiscal Behavior in Latin America". Studies in Comparative International Development, vol. 39, no 1, pp. 3-27.

BEVILAQUA, Afonso S. (2002), "State Government Bailouts in Brazil”. Working Paper, R-441, Inter-American Development Bank.

BEZERRA, Marcos Otávio. (1999), Em Nome das "Bases": Política, Favor e Dependência Pessoal. Rio de Janeiro, Relume Dumará.

CANITROT, Adolfo. (1975), “La Experiencia Populista de Distribución de Renta”. Desarrollo Económico, vol. 15, no 59, pp. 331-351.

COX, David e OAKES, David. (1984), Analysis of Survival Data. London, Chapman \& Hall.

FIGUEIREDO, Argelina e LIMONGI, Fernando. (1999), Executivo e Legislativo na Nova Ordem Constitucional. Rio de Janeiro, Editora FGV.

KALBFLEISCH, John D. e PRENTICE, Ross L. (1980), The Statistical Analysis of Failure Time Data. New York, John Wiley.

KIEFER, Nicholas M. (1988), “Economic Duration Data and Hazard Functions”. Journal of Economic Literature, vol. 26, no 2, pp. 646-679.

KORNAI, János. (1986), “The Soft Budget Constraint”. Kyklos, vol. 39, no 1, pp. 3-30.

KUGELMAS, Eduardo, SALLUM JR., Brasilio e GRAEFF, Eduardo. (1989), “Conflito Federativo e Transição Política". São Paulo em Perspectiva, vol. 3, no 3, pp. 95-102.

LÄCHLER, Ulrich. (1984), “The Political Business Cycle under Rational Voting Behavior”. Public Choice, vol. 44, pp. 411-430.

LANCASTER, Tony. (1990), The Econometric Analysis of Transition Data. Cambridge, Cambridge University Press.

MEJÍA ACOSTA, Andrés e COPPEDGE, Michael. (2001), Political Determinants of Fiscal Discipline in Latin America, 1979-1998. Trabalho apresentado no XXIII congresso internacional da Latin American Sudies Association, Washington, DC, 5-8 de setembro.

MELO, Marcus André B. C. de. (2005), “O Leviatã Brasileiro e a Esfinge Argentina: Os Determinantes Institucionais da Política Tributária”. Revista Brasileira de Ciências Sociais, vol. 20, no 58, pp. 91-129.

MENDES, Marcos. (1999), “Aspectos Institucionais da Performance Fiscal de Estados e Municípios". Revista de Economia Política, vol. 19, no 1, pp. 145-157.

NEIVA, Pedro R. Pereira. (2006), “Os Determinantes da Existência e dos Poderes das Câmaras Altas: Federalismo ou Presidencialismo?". DADOS, vol. 49, no 2, pp. 269-299. 
NORDHAUS, William. (1975), "The Political Business Cycle". Review of Economic Studies, vol. 42, no 2, pp. 169-190.

PEREIRA, Carlos e MUELLER, Bernardo. (2002), “Comportamento Estratégico em Presidencialismo de Coalizão: As Relações entre Executivo e Legislativo na Elaboração do Orçamento Brasileiro". DADOS, vol. 45, no 2, pp. 265-301.

PEREIRA, Carlos e RENNÓ, Lucio. (2001), “O que É que o Reeleito Tem? Dinâmicas Político-Institucionais Locais e Nacionais nas Eleições de 1988 para a Câmara dos Deputados". DADOS, vol. 44, no 2, pp. 323-362.

POTERBA, James M. (1996), "Budget Institutions and Fiscal Policy in the U.S. States". American Economic Review, vol. 82, no 2, pp. 395-400.

ROGOFF, Kenneth. (1990), "Equilibrium Political Budget Cycles”. American Economic Review, vol. 80, no 1, pp. 21-36.

SAMUELS, David. (1998), Careerism and its Consequences: Federalism, Elections, and Policymaking in Brazil. Tese de doutorado, University of California, San Diego.

SOUZA, Celina. (2003), “Federalismo e Conflitos Distributivos: Disputa dos Estados por Recursos Orçamentários Federais". DADOS, vol. 46, no 2, pp. 345-384.

SPILLER, Pablo T. e TOMMASI, Mariano. (2007), The Institutional Foundations of Public Policy in Argentina. Cambridge, Cambridge University Press.

STEIN, Eduardo. (1999), “Fiscal Decentralization and Government Size in Latin America". Journal of Applied Economics, vol. II, no 2, pp. 357-391.

TER-MINASSIAN, Teresa. (1997), Fiscal Federalism in Theory and Practice. Washington, DC, International Monetary Fund.

VON HAGEN, Jürgen. (1991), "A Note on the Empirical Effectiveness of Formal Fiscal Restraints". Journal of Public Economics, vol. 44, no 2, pp. 199-210.

WOOLDRIDGE, Jeffrey. (2001), Econometric Analysis of Cross Section and Panel Data. Cambridge, The MIT Press. 
Aprovação de Empréstimos a Governos Subnacionais no Brasil...

\section{APÊNDICE A ESTATÍSTICAS ADICIONAIS}

Tabela A.1

Estatísticas Básicas das Variáveis Usadas nos Testes Semiparamétricos e Paramétricos

\begin{tabular}{l|c|c|c|c}
\hline Variáveis & Média & Desvio Padrão & Mínimo & Máximo \\
\hline GovPresCAE & 0,40 & 0,49 & 0,00 & 1,00 \\
GovPresCAEChange & 0,07 & 0,25 & 0,00 & 1,00 \\
GovSen & 0,45 & 0,50 & 0,00 & 1,00 \\
GovSenChange & 0,06 & 0,25 & 0,00 & 1,00 \\
GovPres & 0,47 & 0,50 & 0,00 & 1,00 \\
GovPresChange & 0,14 & 0,34 & 0,00 & 1,00 \\
GDPpercapita & 5,66 & 2,60 & 1,35 & 14,44 \\
Nnumber & 2,36 & 1,52 & 1,00 & 10,00 \\
Res78 & 0,22 & 0,42 & 0,00 & 1,00 \\
\hline
\end{tabular}

Tabela A.2

Teste da Hipótese de Risco Proporcional

\begin{tabular}{l|c|c|c}
\hline \multirow{2}{*}{ Teste global } & $\chi^{2}$ & Df & Probabilidade \\
\cline { 2 - 4 } & 22,83 & 4 & 0,0001 \\
\hline
\end{tabular}

Tabela A.3

Teste do (Melhor) Risco Proporcional por Co-Variada

\begin{tabular}{l|c|c|c|c}
\hline Variáveis & Razão de Risco & $\chi^{2}$ & Df & Probabilidade \\
\hline Nnumber & 0,03154 & 0,52 & 1 & 0,4727 \\
GovPresChange & 0,08709 & 4,10 & 1 & 0,0428 \\
GovSen & 0,02459 & 0,33 & 1 & 0,5628 \\
GovSenChange & 0,14975 & 10,05 & 1 & 0,0015 \\
Teste Global & - & 19,52 & 4 & 0,0006 \\
\hline
\end{tabular}




\section{ABSTRACT \\ Approval of Loans to State Governments in Brazil: Is There Room for Opportunistic Political Behavior?}

The aim of this study was to test whether political influence comes into play in the approval of loans to State governments by the Brazilian National Senate. Although all the requests for loans submitted to the Senate during the period under study were approved, we demonstrate that the time required for approval depends on the political relationship between the applicant (State Governor) and the Senate members occupying key positions in the review process. Using "survival analysis" technique, we observed that when the State Governor requesting the loan and the Senator reporting on the matter belong to the same party coalition that helped elect the Governor, loans are approved in less time. On the other hand, approval takes longer if the partisan relationship is broken during the loan review process. Finally, we observed that the more loan applications from a single State in the previous six months, the longer the approval time for a new request. This analysis considered all State loan applications reviewed by the Brazilian Senate from 1989 to 2001.

Key words: Fiscal Federalism; Senate; States (Survival Analysis); Loan Approval; Public Debt

\section{RÉSUMÉ}

Octroi de prêts à des Gouvernements Sous-Nationaux au Brésil: Peut-il y Avoir une Conduite Politique Opportuniste?

Dans cet article, on cherche à vérifier s'il y a une influence politique dans le processus d'octroi de prêts à des gouvernements sous-nationaux (les États brésiliens) à l'intérieur du Sénat. Bien que toutes les demandes soumises au Sénat pendant la période de 1989 et 2001 aient été approuvées, il reste le fait que le délai pour cette approbation dépend des relations politiques entre le demandeur (le Gouverneur) et les sénateurs qui se trouvent aux postes-clé de l'acheminement de ces demandes. En utilisant la technique "d'analyse de survie" (Survival Analysis), on a pu constater que, si le gouverneur demandeur et le sénateur chargé de son dossier appartiennent à la même coalition ayant élu le gouverneur, le délai d'approbation en sera d'autant plus court. Par contre, ce même délai pourra s'étirer si, pendant le processus, ces rapports sont rompus. On a aussi vérifié que les États qui présentent un grand nombre de demandes pendant une période donnée auront plus de difficultés à se voir approuver une nouvelle demande. On a pris en compte dans cette analyse les autorisations parvenues au Sénat entre 1989 et 2001.

Mots-clé: fédéralisme fiscal; Sénat; États; "analyse de survie" (Survival Analysis); octroi de prêts; dette publique

\section{4}

